\title{
Creation of integrated system for feeding management activities automation in beef breeding
}

\author{
Alshyn Altybayev ${ }^{1}$, Yelena Naydenko ${ }^{1}$, Besarion Meskhi ${ }^{2}$, Andrey Mozgovoy ${ }^{2}$, Dmitriy \\ Rudoy $^{2}$, and Anastasiya Olshevskaya ${ }^{2, *}$ \\ ${ }^{1}$ Scientific Production Center of Agricultural Engineering LTD, Almaty, Kazakhstan \\ ${ }^{2}$ Don State Technical University, 1, Gagarin square, 344003, Rostov-on-Don, Russia
}

\begin{abstract}
The practical aspects of creating a hardware-software complex for digital information technology implementation in beef breeding feeding management system are considered. Based on systematic analysis of fattening enterprises current state in Kazakhstan, the areas most prepared for automation in the activities of feeding management in beef breeding were identified. The basic information processes are structured to ensure the adoption of optimal management decisions to comply with the technological regulations for keeping animals on the feedlot. The architecture of information infrastructure and integration of its hardware and software components are proposed, taking into account the current state of IT-solutions market. The material and technical base of the processes for feeding management activities automating was selected taking into account the current state of IT-solutions market and integration requirements, its software integration was implemented. Some methodological approaches to solving problems of software engineering are substantiated, implementation of which contributes to the achievement of practical results of increasing the management activities efficiency of personnel at the operational level.
\end{abstract}

\section{Introduction}

The modern paradigm of efficiency increasing of the production system is more related to the management of resources at each of its sections. It is aimed at saving labor costs and reducing financial costs in technological operations implementation.

Innovative technologies in agriculture are based on technological modernization, the purpose of which is designed to ensure optimal management of production resources. Production resource management - is a management activity area.

The feeding manager activity is to collect, process and analyze heterogeneous data for making management decisions. The specifics of decision-making in this case is in the fact that diet technical and technological calculations should be targeted to individual animal (bull) state, which is associated with the tasks of identification and traceability of each

\footnotetext{
${ }^{*}$ Corresponding author: nati.ugrekhelidze@mail.ru
} 
object of livestock industry. The latter can be done only by modern software and hardware systems [1-3].

The modern market of IT solutions offers a fairly large assortment of products from individual elements of technical solutions to a software platform with multimillion-dollar acquisition and operation costs. At the same time, in digital technologies implementation in real production processes, it most often faces the problem of lack of engineering solutions in creating integrated systems that meet the specific technological operations requirements. In this regard, the task of justifying the integrated approach methodology in the context of a specific production cycle in real production processes system arises.

\section{Purpose of the study}

To form a scientific and methodological base and technological methods for creating an applied hardware and software complex for information and digital technologies introduction in the feeding management system in beef breeding.

\section{Methods and materials}

The main methodological base of the study is the principles of systematic approach, the general principles of creating information systems, the provisions set forth in the writings of leading domestic and foreign scientists dealing with problems of applied informatics, as well as the provisions of theories and practices in the field of beef breeding in Kazakhstan. General research methods include: study, analysis, generalization and systematization of special literature on the research problem; analysis of legislative acts and normative and technical documentation; infological modeling, conversation and interviews with experts and scientists in the field of beef breeding.

The study of feedlot production and technological activities infrastructure in Kazakhstan was carried out on the basis of review and analysis of scientific and technical information from the National Library of Kazakhstan Republic funds, the Scopus database and other Internet resources. Also, there was conducted a survey and questioning of scientists and specialists involved in production and technological processes scientific support and its practical implementation in beef breeding.

The analysis of information models for the RFID system development and implementation in the field of beef breeding was carried out on the basis of the study of world leaders, developing RFID systems, experience.

The systematic representation formation of the subject area of the object of study is implemented on the basis of technical and technological regulations governing the feeding site activities in Kazakhstan, as well as in accordance with ST RK 34.015-2002.

\section{Results and discussion}

Analysis of meat cattle products production system in Kazakhstan [4-7] from making operational management decisions process automating perspective indicates that fattening enterprises have not yet reached sufficient infrastructure for activities comprehensive automation in general.

As a subject area of design and research, a feedlot is considered, which context model covers the period of animals' final preparation for delivery to a meat factory. The production and technological essence of its functioning is to bring the bull live weight due regulated time with the lowest maintenance cost. 
The conceptual architecture of integrated system for feeding management activities automation in beef breeding is presented in the figure 1 .

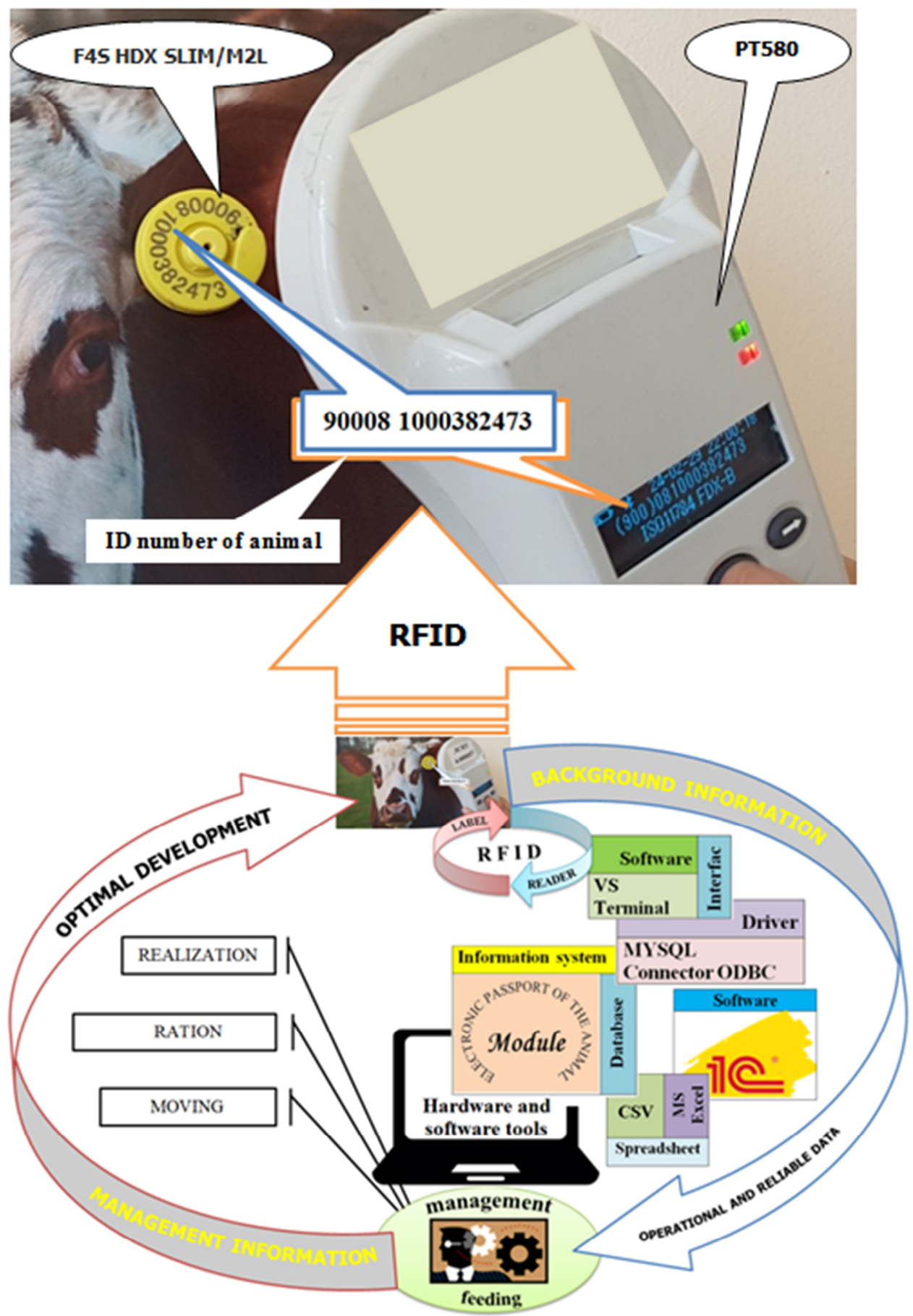

Fig. 1. Simplified architecture of integrated system for feeding management activities automation in beef breeding. 
It reflects the managerial activity information model of feeding manager in beef breeding at the operational level, which functioning is designed to ensure the effective processing of operational data into management information, to maintain the optimal development of animal feeding technological regulation. At the same time, the main components of operational information are the each animal state data, as well as the speed and reliability of the receipts for assessment and analysis (right sector), and the control information main elements are decisions on feeding ration appointment in accordance with the animal state, on its transfer to a group of a certain technological status, and, finally, on implementation of the animal and its withdrawal from the balance (left sector). [8-14]

The presented structure is minimal; all of these blocks must be presented in integrated system created as part of feeding management tasks. Further development of fattening enterprise information infrastructure as a whole can be realized by additional inclusion of other database modules, data exchange interfaces with various software packages, electronic libraries, etc.

The software and hardware tools of the automated management system are implemented as follows. The part of the integrated system that is associated with the registration and transmission of signals in the IT solutions market is presented in sufficient detail. Its design can be limited to the selection of appropriate characteristics, based on the subject area specific processes. It also needs to be configured within this network technology [15-16]. In current work, we used the following elements of RFID technology, based on physical and technical characteristics and operational indicators, as well as taking into account system requirements as applied to the feeding management activities in a feedlot: a set of tags for cattle and MPC F4S HDX SLIM / M2L and a manual RFID reader PT580, the main technical characteristics of which are given in the table.

Table 1. Main specifications of the PT580 RFID reader.

\begin{tabular}{|l|l|}
\hline CPU & ARM (stm32) \\
\hline Working frequency & $134.2 \mathrm{kHz} / 125 \mathrm{kHz}$ \\
\hline Data storage & $7000 \mathrm{records}$ \\
\hline Reading standard & ISO $11784 / 11785$, FDX-B, HDX and ID64 \\
\hline Tag reading distance & $17-20 \mathrm{~cm}$ \\
\hline Countinious working time & 12 hours \\
\hline
\end{tabular}

Developed and installed VS Terminal software for reading RFID tags. Software integration of RFID technology identification system is implemented using software developed in Borland Delphi 7 environment for reading RFID tags mounted on an animal. The ID number of the animal, which is read from the tag, is entered into the computer program, which can be loaded into the information system for subsequent processing and analysis. [17-20],

The core of the software and hardware tools of the feeding manager is the information system where the animal database is formed - Electronic Passport. It is advisable to develop this system on MicrosoftVisualStudio platform. Unlike others, this platform is very flexible and can quickly compile the program algorithm and execute it. The IP contains all the standard and improved reporting forms necessary for control and accounting functions implementation of animal feeding manager activities. The system allows to generate various summary and analytical reports on any data for the required time period. It is possible to upload generated reports in Excel. The IP database has the ability to change, delete, add data.[21-22]

Integration software for RFID technologies with an information system for automated recording of the control object state, i.e. animal, installed on a laptop and launched by clicking the program shortcut on desktop. After starting VS Terminal Software, a start window opens. Next, we bring the reader to the computer on which the VS Terminal 
software is running, information from the reader is transferred automatically, since the program interacts with an external device (reader) via the COM-port built into the computer. Now, when receiving new data from the reader, the program will automatically put data to the database.

Then, after setting up the "Connect" navigation bar and the "Scan" key on the reader, the program receives data from RFID tag.

The animal identification number, read from the tag, is displayed in the software dialog box.

The software is connected to the database with MYSQL Connector ODBC driver. This driver is used to interact with MySQL DBMS through the database access program interface (ODBC). Using ODBC, interaction with any database becomes simple, as it uses a standard interface for interacting with various DBMSs. So, for each DBMS, there is no need to write a separate code for interaction with a specific DBMS.[23]

For integration from the database into $1 \mathrm{C}$ : the company uses the "Export" function, where the recorded data is saved in CSV format, intended for the presentation of tabular data through program code. The program used the CSV extension, since this extension is supported by many applications and is used to import / export tabular data between two different computer programs, for example, in our case - database and spreadsheet. Integration can also be carried out directly between RFID readers and 1C program: Enterprise by: data exchange using http-requests; data exchange by downloading from a file in $1 \mathrm{C}$; data exchange using special $1 \mathrm{C}$ drivers. Next is presentation of the data and its processing according to the standard program of $1 \mathrm{C}$ : Enterprise platform, for example, keeping records of animals in total accounting, in heads and live weight for growing and fattening, as well as costs, profits, etc.

Experimental testing of the integrated system has shown functional performance, and its use in real production conditions increases the profitability of fattening enterprises due to a significant reduction in the time of collecting and processing data of animal feeding management activities.

\section{Conclusions}

The creation and implementation of modern information, communication, and digital technologies in real production should begin with a detailed system analysis of the subject area with the participation of high-level specialists in various aspects of substantiating the information infrastructure of both individual sections and the manufacturing enterprise as a whole. The modern market of IT-solutions allows to implement any organizational and technical solution with a set of production-necessary properties for management activities automation. An integrated information system was developed and tested to automate the feeding management activities in beef breeding, which use increases the feedlot efficiency.

\section{References}

1. V.V. Mazur, K.A. Barmuta, S.S. Demin, E.A. Tikhomirov, M.A. Bykovskiy, Innovation clusters: Advantages and disadvantages. International Journal of Economics and Financial Issues (2016)

2. I.I. Doronina, V.N. Borobov, E.A. Ivanova, E.V. Gorynya, B.M. Zhukov, Agroindustrial clusters as a factor of increasing competitiveness of the region. International Journal of Economics and Financial Issues (2016)

3. A.E. Chernaya, M.N. Kabanenko, S.N. Ugrimova, Improvement of agro-industrial complex management at the federal level. IOP Conference Series: Earth and 
Environmental Science (2019)

4. A.V. Gridchina, L.L. Orekhova, S.V. Lyubimtseva, N.V. Yakovenko, I.V. Komov, Agrarian policy of the region in terms of economic development innovation. International Journal of Economics and Financial Issues (2016)

5. S. Sidorenko, E. Trubilin, E. Kolesnikova, H. Hasegawa, Mechanization in Asia, Africa and Latin America 48(2), 31-35 (2017)

6. A.K. Subaeva, N.V. Malinina, Life Science Journal 11(9).76, 360-362 (2014)

7. V.P. Dimitrov, L.V. Borisova, I.N. Nurutdinova, V.I. Pakhomov, V.P. Maksimov, The problem of choice of optimal technological decisions on harvester control. MATEC Web of Conferences (2018)

8. F.A. Kipriyanov, P.A. Savinykh, Assessment of Technical Provision in Agricultural Sector Of Russia. Eurasian Journal of Biosciences. Foundation for Enviromental Protection and Research (2019)

9. D.K. Muratov, Enhancement of the air-sieve cleaning of the harvester-thresher. The $6^{\text {th }}$ International science and technology conference "Innovative technologies and technical means for field cultivation in the south of Russia" (Zernograd, 2011)

10. Y. Tsarev, E. Adamcikova, M. Najie, Automatization of settings of working organs of technological process of combine harvester. MATEC Web of Conferences (2018)

11. A. Izmailov, M. Moskovskiy, D. Podlesniy, Development of a set of working units from polymeric materials for the design of combine harvesters. MATEC Web of Conferences (2018)

12. D.K. Muratov, Y.I. Ermoliev, Bulletin of Don State Technical University 8(59), 1372$1376(2011)$

13. I. Khozyaev, V. Ladyanov, L. Enalyeva, M. Balinskaya, V. Zharov, Assessment of grain losses during harvesting of grain crops on the basis of technical and economic indicators. E3S Web of Conferences (2019)

14. Russian Federal Standard GOST 34393-2018

15. B.C. Meshi, D.M. Zozulya, A.E. Safronov, Economic evaluation of the efficiency of technosphere safety improvement projects (Don State Technical University, Rostovon-Don, 2013)

16. S.I. Kambulov, I.V. Bozhko, A.V. Olshevskaya, MATEC Web of Conferences 224, 05022 (2018) https://doi.org/10.1051/matecconf/201822405022

17. Yu.A. Ivanov, V.I. Pakhomov, S.I. Kambulov, D.V. Rudoi, ICMTMTE 2018 MATEC Web of Conferences 224, 05023 https://doi.org/10.1051/matecconf/201822405023

18. A. Altybayev, A. Zhanbyrbayev, B. Meskhi, D. Rudoy, A. Olshevskaya, A. Prohorova, E3S Web of Conferences 135, 01078 https://doi.org/10.1051/e3sconf/201913501078

19. B. Meskhi, B. Golev, V. Efros, D. Rudoy, A. Olshevskaya, V. Zhurba, Y. Chayka, E3S Web of Conferences 135, 01083 (2019) https://doi.org/10.1051/e3sconf/201913501083

20. J. Gerber, A. Zavaly, A. Gavrilov, A. Olshevskaya, N. Kiyan, IOP Conf. Series: Earth and Environmental Science 403, 012014 (2019) doi:10.1088/1755-1315/403/1/012014

21. G. Parkhomenko, S. Kambulov, A. Olshevskaya, A. Babadzhanyan, N. Gucheva, I. Mekhantseva, IOP Conf. Series: Earth and Environmental Science 403, 012144 (2019) doi:10.1088/1755-1315/403/1/012144

22. Y. Lachuga, A. Soloviev, A. Matrosov, I. Panfilov, V. Pakhomov, D. Rudoy, IOP 
Conf. Series: Earth and Environmental Science 403, 012055 (2019) doi:10.1088/1755$1315 / 403 / 1 / 012055$

23. E. Zubrilina, I. Markvo, V. Novikov, A. Beskopylny, L. Vysochkina, D. Rudoy, A. Butovchenko, IOP Conf. Series: Earth and Environmental Science 403, 012063 (2019) doi:10.1088/1755-1315/403/1/012063 